PREDIKCIJA BRZINE TRČANJA

DEVOJČICA NA OSNOVU

SNAGE

\section{PREDICTION OF RUNNING \\ SPEED IN GIRLS ON THE BASIS \\ OF STRENGTH}

\section{SAŽETAK}

Cilj istraživanja bio je da se ispita povezanost motoričke sposobnosti snage sa postizanjem rezultata u sprinterskom trčanju radi definisanja testova snage kojima se može vršiti selekcija na časovima fizičkog vaspitanja u uzrastu ranog puberteta. Uzorak je činilo 88 ispitanika ženskog pola uzrasta 12 godina ( \pm 6 mjeseci). Za procenu motoričke sposobnosti snage korištena je baterija od četiri testa koji su propisani nastavnim planom $i$ programom predmeta Fizičko vaspitanje Pedagoškog saveza Vojvodine: varijable eksplozivne snage skok u dalj iz mesta (cm), bacanje medicinke iz ležanja na leđima (m), varijabla repetitivne snage - podizanje trupa (broj uspešnih pokušaja) $i$ varijabla izometrijske snage - izdržaj u visu zgibom (s). Za procenu motoričke sposobnosti brzine primenjen je standardizovani test koji je predstavljao kriterijumsku varijablu - rezultat postignut u trčanju na $60 \mathrm{~m}(\mathrm{~s})$. Povezanost sistema prediktorskih varijabli sa kriterijumskom varijablom izračunat je linearnom regresionom analizom, a rezultati istraživanja su pokazali da se na osnovu rezultata prediktorskog sistema varijabli statistički značajno može predvideti nivo sprinterske brzine trčanja. Pojedinačnim posmatranjem varijabli može se uočiti da varijable skok u dalj iz mesta $(p=0,00)$ i podizanje trupa $(p=0,00)$ ostvaruju statistički značajno predviđanje brzine trčanja na $60 \mathrm{~m}$. Analizirajući rezultate regresione analize, može se pretpostaviti da se rezultat u trčanju na $60 \mathrm{~m}$ kod selektovanih ispitanica može predvideti na osnovu manifestacija eksplozivne snage nogu i repetitivne snage trupa.

Ključne riječi: sprinterska brzina, snaga, devojčice, eksplozivna snaga, repetitivna snaga. 


\section{UVOD}

Trčanje je prirodni oblik kretanja i osnova svakog vežbanja na kome se temelje mnogi sportovi (Findak, 1987). Pored toga što čini osnovu svakog kretanja i mnogih sportova, može se reći da trčanje ima veoma značajan uticaj na celokupno zdravlje ukoliko se upražnjava $u$ prirodnim i zdravim uslovima (Janković, 1998). Trčanje je definisano u centralnom nervnom sistemu, a njegova efikasnost, odnosno brzina, zavisi od niza urođenih funkcija (Babić i Čoh, 2010). Smatra se da funkcionalne i motoričke sposobnosti spadaju među najodgovornije za uspeh u trčanju na kratke staze (Homenkov, 1977, Milanović, 2007, Mihajlović i Tončev, 2008), a kao najvažniji faktori za postizanje visokih rezultata na kratkim stazama smatraju se dobra tehnika, brzina alternativnih pokreta, eksplozivna snaga i maksimalna sila pokušanih pokreta. Maksimalna brzina koju čovek može ispoljiti u bilo kakvom pokretu zavisi od niza različitih faktora koji su vezani na morfološke i fiziološke karakteristike, energetske mehanizme, pol, starost, biomotoričke sposobnosti, inter i intra mišićnu koordinaciju i optimalnu biomehaniku tehnike kretanja (Čoh i Bošnjak, 2010). Kada se govori o trčanju za decu, onda se misli na „prirodni biološki razvoj sprinterske brzine“ (Babić i Čoh, 2010) na koji najviše utiču telesna visina i telesna masa, razvoj motoričkih sposobnosti i formiranje motoričkih stereotipa. Uspešnost deteta u sprinterskim disciplinama zavisi, između ostalog, i od perioda kada dete počinje da trenira - poželjno je da dete trening brzine počne pre puberteta, jer taj period karakteriše uravnotežen i proporcionalan razvoj, kao i funkcionalno sazrevanje (Bompa, 2000). Pošto je brzina tipa sprinta vrlo važna sposobnost koja uslovljava uspješnost sportiste u velikom broju situacija tokom njegove sportske karijere (Babić i Čoh, 2010), ovde će biti riječi o toj aktivnosti. Sprintersko trčanje je najbrži oblik prirodnog kretanja čoveka i sastoji se od ponavljajućih trkačkih koraka (Ibid), tačnije, predstavlja niz eksplozivnih skokova ukomponovanih u jednu skladnu celinu, čiji je osnovni zadatak postizanje maksimalne brzine trčanja za što kraće vreme i očuvanje dostignute brzine što je duže moguće (Marinković, 1977). U brzim terminalnim pokretima tipa sprinta razvijanje sile je ključni faktor efikasnosti kretanja, kod kojih su varijable motornog programa maksimalna sila agonista, maksimalna sila antagonista, vreme kašnjenja antagonista, vreme postizanja maksimalne sile antagonističkih mišića, koaktivacioni odnos mišića u funkciji položaja kinetičkog lanca, dužina pokreta, terminalni položaj, početni položaj, vreme trajanja pokreta i brzina pokreta (Ilić, 1999). Pošto dečijem uzrastu odgovaraju brža kretanja, ovakva kretanja su veoma povoljna i u skladu sa mladim organizmom (Ibid), a savladavanje pravilne tehnike sprinterskog trčanja važno je za prevenciju povreda i nekontrolisanih padova uzrokovanih slabom izvedbom trčanja i slabijom koordinacijom pokreta koja nije primerena brzini trčanja. Poznato je da se najvažnije sposobnosti i osobine za bavljenje atletskim disciplinama najbolje razvijaju u određenim, senzitivnim razdobljima života (Sozanski, 1981; Zeličenok, 1998), a pretpostavlja se da se najveće povećanje brzine trčanja može postići ako se trening započne pre puberteta. Tada se brzina prirodno razvija: od 7. do 11. godine, odnosno od 13. do 14. godine kod devojčica, te od 7. do 10. i od 15. do 16. godine kod dečaka (Sozanski, 1981). Vraneković, Tkalčić i Horvatin-Fučkar (2008) istraživali su relacije između antropometrijskih dimenzija i trčanja na $60 \mathrm{~m}$ na uzorku od 345 učenika uzrasta od 13 godina \pm 6 meseci. Rezultati su pokazali da antropometrijske varijable i u manifestnom i u latentnom prostoru imaju značajan uticaj na rezultat sprinterskog trčanja. S obzirom na nužnost pravovremene orijentacije dece za atletske discipline važno je biti u mogućnosti napraviti efikasnu i primenljivu proveru onih sposobnosti i obeležja koja imaju doprinos u ostvarivanju boljeg rezultata u sprinterskom trčnju. Stoga, cilj ove studije je bio da se ispita povezanost motoričke

Radulović, N., et al.: Predikcija brzine...Sportlogia 2017, 13 (1), 38-45. Stranica 39. 
sposobnosti snage sa postizanjem rezultata u sprinterskom trčanju radi definisanja testova snage kojima se može vršiti selekcija na časovima fizičkog vaspitanja u uzrastu ranog puberteta.

\section{METOD RADA}

Istraživanje je transverzalnog karaktera i provedeno je tokom dve sedmice na časovima fizičkog vaspitanja, na kojima je, nakon adekvatne pripreme, kroz uvodni i pripremni dio časa, u toku glavnog dela časa na prvom času utvrđena vrednost varijable brzine, a na drugom vrednosti varijabli snage. Uzorak se sastojao od 88 devojčica (12 godina \pm 6 mjeseci) petog razreda osnovne škole, odabrane metodom slučajnog izbora. Sistematskim pregledom utvrđeno je da su bile zdrave i bez povreda lokomotornog aparata. Takođe, nisu bile uključene u neki trenažni proces, nisu se bavile organizovanim rekreativnim aktivnostima, niti su za provođenje istraživanja bile pripremane nekim programom vežbanja.

$\mathrm{Za}$ procenu motoričke sposobnosti snage korišćena je baterija od četiri testa, koji su propisani nastavnim planom i programom predmeta Fizičko vaspitanje Pedagoškog saveza Vojvodine: varijable eksplozivne snage - skok u dalj iz mesta $(\mathrm{cm})$, bacanje medicinke iz ležanja na leđima (m), varijabla repetitivne snage - podizanje trupa (broj uspešnih pokušaja) i varijabla izometrijske snage - izdržaj u visu zgibom (s). Za procenu motoričke sposobnosti brzine primenjen je standardizovani test koji je predstavljao kriterijumsku varijablu - rezultat postignut u trčanju na $60 \mathrm{~m}(\mathrm{~s})$.

Primenom statističkog programa SPSS 20.0 izračunati su osnovni statističkih parametri (aritmetička sredina i standardna devijacija), dok je kod unapred formiranog subuzorka devojčica, s ciljem utvrđivanja povezanosti i predikcije sistema prediktorskih varijabli sa kriterijumskom varijablom, bila primenjena linearna regresiona analiza.

\section{REZULTATI}

Tabela 1. Deskriptivna statistika analiziranih varijabli

\begin{tabular}{cccc}
\hline Varijabla & AS & SD & KS test \\
\hline Skok u dalj iz mjesta & 177,20 & 24,310 & 0,13 \\
\hline Bacanje medicinke iz ležanja na leđima & 5,73 & 4,18 & 0,73 \\
\hline Podizanje trupa & 39,54 & 7,129 & 0,18 \\
\hline Izdržaj u zgibu & 53,08 & 26,529 & 0,49 \\
\hline Trčanje 60 m & 12,30 & 3,993 & 0,32 \\
\hline
\end{tabular}

Legenda: AS - aritmetička sredina; SD - standardna devijacija; KS test - Kolmogorov Smirnov test

U Tabeli 1. prikazani su centralni i disperzioni parametri. Na osnovu njih može se zaključiti da su najveće vrednosti standardnih devijacija primećene kod testova skok u dalj iz mesta i izdržaj u zgibu, što ukazuje na činjenicu da su rezultati kod tih testova najviše odstupali od prosečnih vrijednosti ovog uzorka ispitanika. To se može pripisati raznolikim dnevnim fizičkim aktivnostima dece u slobodno vreme. Kada se govori o homogenosti rezultata, zaključuje se da je najveća homogenost rezultata oko aritmetičke sredine kod testova rezultat postignut u trčanju na $60 \mathrm{~m}$ i bacanju medicinke iz ležanja na leđima.

Radulović, N., et al.: Predikcija brzine...Sportlogia 2017, 13 (1), 38-45. Stranica 40. 
U Tabeli 2. prikazani su rezultati regresione analize motoričkih sposobnosti, odnosno analiza predikcije prediktorskog sistema na kriterijumsku varijablu, odnosno na rezultat postignut u trčanju na $60 \mathrm{~m}$ kod devojčica.

Tabela 2. Regresiona analiza

\begin{tabular}{lcccccc}
\hline Varijabla & $\mathrm{r}$ & $\mathrm{p}$ & $\mathrm{r}_{\text {part }}$ & $\mathrm{p}_{\text {part }}$ & Beta & $\mathrm{p}_{\text {bete }}$ \\
\hline Skok u dalj iz mjesta & 0,67 & 0,00 & 0,08 & 0,001 & $-0,576$ & 0,001 \\
\hline Bacanje medicinke iz ležanja na leđima & 0,62 & 0,00 & 0,02 & 0,523 & 0,156 & 0,523 \\
\hline Podizanje trupa & 0,64 & 0,00 & $-0,11$ & 0,000 & $-0,135$ & 0,000 \\
\hline Izdržaj u zgibu & 0,59 & 0,00 & 0,24 & 0,397 & $-0,123$ & 0,397 \\
\hline & $\mathbf{R}=\mathbf{0 , 6 3 3}$ & $\mathbf{R}^{2}=\mathbf{0 , 4 9 2}$ & $\mathbf{P}=\mathbf{0 , 0 0 0}$ & &
\end{tabular}

Legenda: $r$ - Pirsonov koeficijent korelacije; $p$ - nivo statističke značajnosti za $r ; r_{p a r t}$ - vrednost koeficijenta parcijalne korelacije; $p_{\text {part }}$ - nivo statističke značajnosti za $r_{\text {part, }}$ Beta - regresijski koeficijent; pbete - nivo značajnosti regresijskog koeficijenta; $\mathrm{R}$ - koeficijent multiple korelacije; $\mathrm{R}^{2}$ - koeficijent determinacije; $\mathrm{P}$ - značajnost koeficijenta multiple korelacije

Uvidom u ovu tabelu utvrđeno je da se rezultati ispitivanog kriterijuma statistički značajno mogu predvideti na osnovu rezultata sistema prediktorskih varijabli $(\mathrm{p}=0,00)$ pri vrednosti koeficijenta multiple korelacije $\mathrm{R}=0,633$, što objašnjava $49,2 \%$ zajedničkog varijabiliteta, dok se ostali procenat može pripisati nekim drugim činiocima koji nisu obuhvaćeni datim prediktorskim sistemom, a direktno su povezani sa efikasnošću izvođenja tehnike sprinterskog trčanja i postizanja rezultata (dužina koraka, faze odupiranja, trajanje kontakta stopala sa podlogom, druge longitudinalne dimenzije, kognitivne i konativne karakteristike, stanje mišića, inter i intra koordinacija mišića). Takođe, posmatrajući pojedinačno rezultate pojedinih varijabli, može se zaključiti da se rezultati kriterijumske varijable mogu statistički značajno predvideti na osnovu rezultata varijabli skok u dalj iz mesta $(p=0,00)$ i podizanje trupa $(\mathrm{p}=0,00)$. Devojčice sa većim vrednostima navedenog prediktorskog sistema varijabli su ostvarile bolje rezultate u testu za procenu brzine trčanja, što znači, da bi se detaljnijim i daljim treningom na manifestaciji eksplozivne snage nogu i repetitivne snage trupa moglo doprineti poboljšanju rezultata $\mathrm{u}$ trčanju na $60 \mathrm{~m}$ kod ovih ispitanica. Takođe, na osnovu Pirsonovog koeficijenta korelacije, zaključuje se da su ispitanici sa većim vrednostima u varijabli za procenu motoričkih sposobnosti snage ostvarili statistički značajnije $(\mathrm{p} \leq 0,01)$, bolje rezultate u testu za procenu sprinterske brzine.

Rezultati parcijalne korelacije iz iste tabele ukazuju da u najvećoj meri rezultat trčanja na $60 \mathrm{~m}$ determinišu varijable skok $u$ dalj iz mjesta $\left(\mathrm{p}_{\mathrm{part}}=0,001\right)$ i podizanje trupa $\left(\mathrm{p}_{\mathrm{part}} \mathrm{p}=0,000\right)$. Može se konstatovati da preostale analizirane varijable za procenu ostalih vidova snage eksplozivna snaga ruku (bacanje medicinke iz ležanja na leđima) i izdržljivost u snazi (izdržaj u zgibu), umanjuju mogućnost ostvarivanja boljih rezultata kod ovog uzorka ispitanica (nakon parcijalizacije, koeficijent parcijalne korelacije se znatno smanjio u odnosu na Pirsonov koeficijent). 


\section{DISKUSIJA}

Istraživanje je pokazalo relativno podjednaku predikciju rezultata kriterijumske varijable na osnovu rezultata seta prediktorskih varijabli, koje su analizirale razne vidove snage, što jasno ukazuje na važnost utvrđivanja faktora povezanih sa sprinterskim trčanjem. Zagorac (1984) je istraživao povezanost motoričkih sposobnosti kod trčanja na $600 \mathrm{~m}$ (između ostalih testova), i dokazao da su motoričke sposobnosti veoma povezane sa rezultatom u trčanju, i to pozitivno, što znači da razvojem motoričkih sposobnosti može da se poboljša rezultat u trčanju dece uzrasta 1113 godina. Mihajlović i Tončev (2008) tvrde da se u dobi od 14. do 19. godine usvajaju odlučujući delovi tehnike za vrhunski rezultat u budućem takmičenju, te tako smatraju da je veoma bitna činjenica da se dvije godine pre toga počne sa razvojem motoričkih sposobnosti i poboljšanjem njihovog nivoa, kako bi se kasnije usavršila tehnika i došlo do najboljih rezultata. Istraživački projekat MZOS RH, koji je proveden 2003/2004. godine, sadržao je istraživanje koje se odnosilo na decu osnovnoškolskog uzrasta, a ispitivane su motoričke sposobnosti uz pohađanja atletike, sprinterska trčanja, kao dodatne fizičke aktivnosti. Dobijeni su rezultati da su se motoričke sposobnosti poboljšale zahvaljujući pohađanju atletske sekcije u obliku sprinterskog trčanja. To znači da, pored razvoja motoričkih sposobnosti zarad poboljšanja rezultata u trčanju na kratke staze, treba uvežbavati i tehniku trčanja na kratke staze kako bi se poboljšao rezultat $u$ trčanju. Većina istraživača u svojim istraživanjima tvrde da je za nivo brzine kao motoričke sposobnosti zaslužan koeficijent urođenosti $95 \%$, dok samo eventualno poboljšanje iste vežbanjem može da bude samo 5\% (Wilmore i Costill, 1994). Zbog složenosti anatomske i fiziološke strukture aparata za kretanje, kao i različite strukture mišićnih vlakana i dimenzija tela pojedinih segmenata čoveka, teško je odrediti idealan model kretanja trkača i trkačica kratkih staza. Zato se u stručnoj i naučnoj literaturi i trenažnoj praksi uglavnom razmatraju pitanja opštih zakonitosti mišićne kontrakcije i uzajamnog delovanja pojedinih grupa mišića za vreme izvođenja maksimalno brzih kretanja. Istraživanja Opavskog (1975) ukazuju da se brzina za vreme trčanja kratkih staza prikazuje u periodu zadnjeg oslonca, dok su dodatni faktori zamah zamajne noge i zamah suprotne ruke. Zbog veće mase i veće amplitude kretanja, $u$ šta ulazi i tehnički detalj kao što je zamah zamajnom nogom, koja predstavlja značajan dio osnovnog faktora da se u periodu zadnjeg oslonca (odupiranja) strana zamajne noge brže kreće od strane odskočne noge. Trkači treba da nastoje da postave prednji dio stopala noge bliže vertikalnoj projekciji težišta tela (u skladu sa brzinom kretanja) da bi se skratila faza amortizacije. Na kraju trkačke deonice dolazi do smanjenja brzine. Uzrok te pojave je konstantni zadatak istraživača, ali najverovatnije je uzrok u promeni funkcionalnog stanja centralnog nervnog sistema i lokalnom umoru aktuelnih mišićnih grupa (Bompa, 2006).

S obzirom da se u ovom istraživanju želelo utvrditi koji od testova za predikciju snage, propisanih programom nastavnog predmeta Fizičko vaspitanje, može poslužiti za procenu predispozicije za trčanje na kratkim stazama u ranom uzrastu devojčica, a s obzirom na sve navedeno, može se konstatovati da se na ovom uzorku pokazala direktna povezanost dva oblika snage - eksplozivne snage nogu i repetitivne snage trupa sa rezultatom trčanja na $60 \mathrm{~m}$. Razvijanje maksimalne brzine zahteva veoma suptilnu međumišićnu koordinaciju mišićnih grupa donjih ekstremiteta, od kojih najvažniju ulogu imaju sledeći mišići: m. gluteus maximus, m. tibialis anterior, m. soleus, $\mathrm{m}$. gastrocnemius, $\mathrm{m}$. rectus femoris, $\mathrm{m}$. biceps femoris, $\mathrm{m}$. vastus lateralis (Čoh i Bošnjak, 2010), što je povezano sa dobijenim rezultatima ovog istraživanja, budući da navedeni mišići obezbeđuju eksplozivnu snagu nogu i zajedno sa trbušnim mišićima (koji obezbeđuju repetitivnu snagu trupa) dio su lanca pokreta potrebnog za efikasno trčanje na

Radulović, N., et al.: Predikcija brzine...Sportlogia 2017, 13 (1), 38-45. Stranica 42. 
kratke staze. Samim tim, utvrđeno je da je na ovom uzorku ispitanica moguće izvršiti selekciju za trčanje na kratke staze na osnovu rezultata postignutih u tim testovima snage, te da navedena dva testa imaju upotrebnu vrednost za procenu motoričke vrednosti brzine i da je potrebno da se i dalje provode u sklopu plana i programa Fizičkog vaspitanja.

\section{ZAKLJUČAK}

Osvrtom na rezultate koji su dobijeni ovim istraživanjem, može se izvesti zaključak da se brzina trčanja, kao motorička sposobnost koja je analizirana testom trčanja na $60 \mathrm{~m}$, kod devojčica uzrasta 12 godina statistički značajno može predvideti na osnovu rezultata nekih testova koji procenjuju različite vidove snage kao motoričke sposobnosti, što je potvrđeno istraživanjem (Babić, 2005; Strel, Bizjak, Starc i Kovač, 2009; Vraneković, Tkalčić i HorvatinFučkar, 2008) koji su na sličnom uzorku ispitanika dokazali da su motoričke sposobnosti pozitivno povezane sa rezultatom kod trčanja na $60 \mathrm{~m}$. Dobijeni rezultati istraživanja pokazali su da nisu sve varijable pokazale statističku značajnost. Varijable koje su se izdvojile kao one koje najviše doprinose poboljšanju ispoljavanja brzine kao motoričke sposobnosti su skok u dalj iz mjesta i podizanje trupa, te se da povećanjem njihovih vrednosti dovodi do poboljšanja ispoljavanja brzine merene testom trčanje na $60 \mathrm{~m}$. Značaj istraživanja ove prirode ogleda se u unapređenju sportske nauke, jer omogućava razumevanje sportsko-motoričke nadarenosti, a samim tim i prognoziranje sportskih dostignuća. Samo postojanje i dostupnost ovakvim istraživanjima razjašnjava problematiku pronalaženja talenata i eliminiše subjektivizam sportskih stručnjaka prilikom selekcije. Poznavanje sposobnosti i osobina koje su presudne za uspeh u sportskim aktivnostima važno je za pravilnu selekciju i usmeravanje potencijalnih sportista, a posebno za programiranje i provođenje nastavnog i trenažnog procesa i praćenje rezultata tih procesa. Analizom dobijenih rezultata sposobnosti mogu se ponuditi konkretna i optimalna rešenja i izbeći se gubitak vremena i pogrešna orijentacija.

\section{LITERATURA}

Babić, V. (2005). Utjecaj motoričkih sposobnosti i morfoloških obilježja na sprintersko trčanje. Doktorska disertacija, Sveučilište u Zagrebu, Kineziološki fakultet.

Babić, V., \& Čoh, M. (2010). Karakteristike razvoja brzine i sprinterskog trčanja [Characteristics of development speed and sprint]. In I. Jukić et al. (Ed.), 8. godišnja međunarodna onferencija Kondicijska priprema sportaša (pp. 83-98). Zagreb, RH: Sveučilište u Zagrebu \& Udruga kondicijksih trenera Hrvatske.

Bompa, T. (2000). Cjelokupni trening za mlade pobjednike [Total training for young champions]. Zagreb, RH: Gopal

Bompa, T. (2006). Teorija i metodologija treninga. Zagreb, RH: Gopal.

Čoh, M., \& Bošnjak, G. (2010). Neuro-mišićne karakteristike maksimalne sprinterske brzine. SportLogia, $6(1), 28-35$. https://doi.org/10.5550/sgia. 1001028

Findak, V., i Mraković, M. (2003). Metode rada u području edukacije, sporta i sportske rekreacije. In K. Delija (Ed.), Zbornik radova 12. ljetne škole kineziologa Republike Hrvatske (pp. 12-19). Rovinj, RH. Hrvatski kineziološki savez.

Findak, V. (1987). Zbornik radova 12. ljetne škole kineziologa Republike Hrvatske. Metode rada u području edukacije, sporta i sportske rekreacije. Zagreb. Hrvatski kineziološki savez.

Radulović, N., et al.: Predikcija brzine...Sportlogia 2017, 13 (1), 38-45. Stranica 43. 
Homenkov, L. S. (1977). Atletika. Beograd, RS: Fakultet fizičke kulture.

Ilić, D. ( 1999). Motorna kontrola i učenje brzih pokreta. Beograd, RS: Zadužbina Andrejević.

PMCid:PMC32217

Janković, M. (1998). Teorija i metodika sportskog treninga. Niš, RS: Univerzitet u Nišu.

Milanović, D. (2007). Teorija treninga - priručnik za studente sveučilišnog studija. Zagreb, RH: Kineziološki fakultet Sveučilišta u Zagrebu.

Marinković, M. A. (1977). Atletika za najmlađe. Beograd, RS: Jež.

Mihajlović, I., \& Tončev, I. (2008). Prediktivne vrijednosti morfološkog i motoričkog sustava za selekciju u sprintu [Predictive values of morphologoical and motor system for sprint selection purposes]. Acta kinesiologica, 2 (1), 95 - 98.

Opavski, P. (1975). Interrelacije biomotoričkih dimenzija i mišićnih naprezanja. Fizička kultura, 29 (4), 53-55.

Sozanski, H. (1981). Selekcija - važan elemenat sistezahtma sportskog treninga. Savremeni trening 3, 34 -37 .

Strel, J., Bizjak, K., Starc, G. \& Kovač, M. (2009). Longitudinalna komparacija razvoja nekih telesnih karakteristika i motoričkih sposobnosti dve generacije djece i omladine od 7. do 18. godina starosti u slovenačkim osnovnim i srednjim školama u razdobljima od 1990-2001. i 1997-2008. In B. Bokan (Ed.), Zbornik radova „,Teorijski, metodološki $i$ metodički aspekti fizičkog vaspitanja” (pp. 21-33). Beograd, RS: Fakultet sporta i fizičkog vaspitanja.

Vraneković, S., Tkalčić, S. \& Horvatin-Fučkar, M. (2003). Analiza rezultata dobivenih mjerenjem bazičnih motoričkih sposobnosti učenica od 5. do 8. razreda Osnovne škole. In K. Delija (Ed.), Zbornik radova 12. ljetne škole kineziologa Republike Hrvatske (pp. 292-294). Rovinj, RH. Hrvatski kineziološki savez.

Wilmore, J. H. \& Costill, D. L. (1994). Physiology of sport and exercise. (Fiziologija sporta i vežbanja). Leisure Press, Champaign IL: Human Kinetics.

Zagorac, N. (1984). Relacije između antropometrijskih i motoričkih karakteristika i rezultata u atletskim disciplinama: skok u dalj, skok u vis i trčanje na 600m kod djece starosne dobi 11-13 godina. Magistarski rad, Fakultet za fizičku kulturu. Zagreb.

Zeličenok, V. B. (1998). Kriteri i otbora kak osnova komplektovanija s bornyh nacionajnyh komand po ljeghoj atletike. Moskva, RUS.

Radulović, N., et al.: Predikcija brzine...Sportlogia 2017, 13 (1), 38-45. Stranica 44. 


\section{SUMMARY}

The aim of this study was to examine connection between the motor ability strength and the achievement of results in sprinting in order to define strength tests to perform selection in physical education classes, at the age of early puberty. The sample consisted of 88 female subjects aged 12 years ( \pm 6 months). The batery of four tests was used for evaluation of the motor ability strength, prescribed in the curriculum for the subject Physical Education of the Pedagogical Association of Vojvodina: variables of explosive strength - standing broad jump $(\mathrm{cm})$, throwing medicine ball from lying position $(\mathrm{m})$, variable of repetitive strength - sit-ups (number of successful attempts) and variable of isometric strength - bent arm hang (s). For evaluation of the motor ability speed, the standardized test was applied, which represented the criterion variable - the result obtained in $60 \mathrm{~m}$ run $(\mathrm{s})$. The relationship between the system of predictor variables and the criterion variable is calculated by linear regression analysis, and the results showed that, on the basis of the results of the predictor variables system, the level of sprinting speed can be statistically significantly predicted. By observing the individual variables, it can be seen that the variables standing broad jump $(p=0.00)$ and sit-ups $(p=0.00)$ achieve statistically significant prediction of $60 \mathrm{~m}$ run speed. By analyzing the results of regression analysis, it can be assumed that the result of the $60 \mathrm{~m}$ run in selected subjects can be predicted based on manifestation of explosive leg strength and repetitive strength of torso.

Key words: sprint speed, strength, girls, explosive strength, repetitive strength. 